\title{
0 trabalho docente como elemento fundamental na garantia do direito à educação
}

\author{
SAMANTA ANTUNES KASPER ${ }^{(1)}$ \\ RENATA PORTELA RINALDI ${ }^{(2)}$
}

Resumo. 0 estudo parte do princípio de que discutir educação é discutir trabalho docente. A educação, considerada como direito humano fundamental e contemplada na legislação nacional e internacional é marcada pela distância entre o direito instituído e o direito efetivado. Para que a implementação do direito social à educação seja garantida é necessário considerar o trabaIho do professor, haja vista que ele é um dos principais agentes educacionais. Assim, nosso artigo dedica-se ao tema do trabalho docente enfatizando o mal-estar presente no exercício profissional do magistério. Os resultados apontam que os fatores que geram o mal-estar docente dividem-se em alta, média e baixa frequência. No que se refere aos fatores de alta frequência destaca-se o desprestígio/ desvalorização social e os baixos salários. No que tange aos fatores que apareceram com frequência média evidencia-se a escassez de recursos e o descaso da família dos alunos. Entre os fatores que compareceram em menores números sobressaem os problemas de aprendizagem, a autoculpabilização e a falta de autonomia. Observou-se que esses elementos trazem inúmeras implicações sobre o trabalho dos professores e que apesar de o mal-estar docente ocupar regularidade entre as análises nas pesquisas educacionais, o mesmo ainda é uma realidade frequente.

Palavras-chave. trabalho docente . direito à educação $\cdot$ mal-estar docente

(1) Estudante do Programa de Pós-Graduação em Educação da unesp/Campus de Presidente Prudente. Membro do Grupo de Pesquisa Formação de Professores e Práticas de Ensino na Educação Básica e Superior. Atua com as seguintes temáticas: formação de professores, trabalho docente, mal-estar docente e educação integral. Possui graduaçáo em Letras pela UnEsP/Campus de Assis, com ênfase em línguas portuguesa e inglesa e suas respectivas literaturas. Realizou intercâmbio na University of Victoria, Canadá (2013), na Uppsala University, Suécia (2015) e na Universidad Nacional del Litoral, Argentina (20I8).samanta_kasper@ hotmail.com
(2) Professora doutora, vinculada no Departamento de Educação e no Programa de Pós-Graduação em Educação da Unesp/Campus de Presidente Prudente. Foi editora da Revista Nuances: estudos sobre educação no biênio 20I6-20I8. Possui graduação em Pedagogia pela UNESP (200I), mestrado (2006) e doutorado (2009) em Educação pela Universidade Federal de Sáo Carlos (ufsCar) com estágio na Université de Genève, Suiça (2009). É líder do Grupo de Pesquisa; Formação de Professores e Práticas de Ensino na Educação Básica e Superior. Atua principalmente nos seguintes temas: formação de professores, estágio supervisionado, processos formativos na modalidade à distância, educação inclusiva, educaçáo integral, educação em tempo integral. renata. rinaldi@unesp.com 


\section{El trabajo docente como elemento fundamental en la garantía del derecho a la educación}

Palabras clave. trabajo docente .

derecho a la educación - malestar docente

Resumen. El estudio parte del principio de que discutir la educación es discutir el trabajo docente. La educación, considerada como derecho humano fundamental, contemplada en la legislación nacional e internacional, está marcada por la distancia entre el derecho instituido y el efectuado. Para que la implementación del derecho social a la educación sea garantizada es necesario considerar el trabajo del profesor, puesto que él es uno de los principales agentes educativos. Así, nuestro artículo se dedica al tema del trabajo docente enfatizando el malestar en los profesores. Los resultados apuntan que los factores que generan el malestar se dividen en alta, media y baja frecuencia. En lo que se refiere a los de alta frecuencia, se destacan el desprestigio/devaluación social y los bajos salarios. En lo referente a los factores que aparecieron con frecuencia media, se evidencian la escasez de recursos y el descuido de la familia de los alumnos. Entre los que menos emergieron, sobresalen los problemas de aprendizaje, la autoculpabilización y la falta de autonomía. Se observó que estos elementos traen innumerables implicaciones sobre el trabajo docente y que, a pesar de que el malestar presenta regularidad entre los análisis en las investigaciones educativas, este sigue siendo una realidad frecuente.

\section{Teaching work as \\ a fundamental element in guaranteeing the right to education}

Palabras clave. teaching work - right to education . teachers' discomfort

Keywords. The starting point of the present study lies in the principle that addressing education means discussing teaching work. Education is considered as a fundamental human right and it is contemplated in national and international legislations. It is marked by the distance between the instituted right and the effective right. For guaranteeing the implementation of the social right to education, it is necessary to consider teachers' work, since he/she is one of the main educational agents. Thus, our study is devoted to the issue of teaching work, emphasizing teachers' discomfort. Results show that the factors that generate teachers' discomfort are divided into three categories according to their occurrence: high, medium, and low frequency. High-frequency factors include social discredit and low wages. As regards the factors found to occur with medium frequency, scarcity of resources and child neglect by family members are evidenced. Among the factors that arose less frequently, learning problems, self-blame, and lack of autonomy can be emphasized. It was observed that these elements bring about many implications for teaching work. Even though teachers' discomfort is a recurring topic among educational research analyses, it is still present in teachers' daily work. 


\section{Introdução}

No Brasil, a Constituição Federal de 1988 (CF 1988) compreende a educação pública como um direito social subjetivo. Responsabilizam-se o Estado e a família por garanti-lo (Art. 205). Ela especifica a competência legislativa, trata dos princípios a serem considerados no ensino por meio da igualdade de condições para o acesso à educação visando a permanência do aluno na escola pública, com padrão de qualidade (Art. 206, incisos I, IV e VII). Regulamenta, também, o financiamento da educação para a União, Estados, Distrito Federal e Municípios (Art. 212), como reconhecimento da importância da educação escolar nos processos de democratização da sociedade. Para tanto, se responsabilizam por dar efetividade a esses dispositivos constitucionais nos diversos sistemas de ensino deste país, os gestores públicos e os profissionais da educação, com o apoio da comunidade.

O Estatuto da Criança e do Adolescente (Lei n 8.069/1990), um marco legal no que diz respeito aos direitos das crianças e dos adolescentes, também coloca em evidência a educação como um direito social que visa o pleno desenvolvimento, o preparo para o exercício da cidadania, a qualificação para o trabalho, mediante a garantia do acesso e da permanência desses indivíduos nas instituições escolares. Contudo, todas as facilidades e oportunidades deverão ser implementadas a eles, sem prejuízo à proteção integral de que trata referida lei, com o objetivo de «lhes facultar o desenvolvimento físico, mental, moral, espiritual e social, em condições de liberdade e de dignidade» (Art. $3^{\circ}$ ).

Em consonância, a Lei de Diretrizes e Bases - LDB (Lei n 9.394/1996), pautada na CF 1988, reconhece que a educação abrange os processos formativos que se desenvolvem na vida familiar, na convivência humana, no trabalho, nas instituições de ensino e pesquisa, nos movimentos sociais e organizações da sociedade civil e nas manifestações culturais. Trata dos princípios educacionais, do direito à educação e do dever em assegurá-la, da organização e do regime de colaboração dos entes da federação em torno dos sistemas de ensino, das especificidades dos diferentes níveis e modalidades de educação e ensino, dos profissionais da educação, entre outros. Todavia, é importante estar atento para o fato de que a responsabilização do Estado não pode ser esquecida, «A educação, direito de todos e dever do Estado e da família, será promovida e incentivada com a colaboração da sociedade» (cf. Brasil, 1988: Art. 205). Não 
pode haver inversão e omissão das responsabilidades do Estado em detrimento das responsabilidades da família como se percebe ao analisar o artigo $2^{\circ}$ da LDB n. 9.394/1996: «A educação, dever da família e do Estado, inspirada nos princípios de liberdade e nos ideais de solidariedade humana, tem por finalidade o pleno desenvolvimento do educando, seu preparo para o exercício da cidadania e sua qualificação para o trabalho».

Nos últimos tempos, temos vivido e observado inúmeras discussões no campo educacional refletindo sobre a qualidade do ensino ofertado. Indicam como um dos principais desafios, fazer com que o direito à educação seja, além de garantido e efetivado por meio de medidas de universalização do acesso e da permanência, uma experiência enriquecedora do ponto de vista humano, político e social e que consubstancie, de fato, um projeto de emancipação e inserção social (Oliveira; Araújo, 2005) a partir, sobretudo, da perspectiva de escola como espaço institucional de produção e de disseminação, de modo sistemático, do saber historicamente produzido pela humanidade (Dourado; Oliveira, 2009). Nesse cenário, tais desafios nos remetem a reflexão sobre o professor e a sua condição de trabalho, uma vez que se espera que esse profissional forme cidadãos condizentes com as exigências da sociedade em consonância com o novo paradigma educacional também chamado de sociedade do conhecimento. Tal afirmação é reforçada por Hargreaves (2004:171) em que ressalta «os professores são as parteiras da sociedade do conhecimento, sem eles, sua confiança e sua competência, o futuro será malformado e natimorto».

A sociedade do conhecimento é definida por Dziekaniak e Rover (2011:s/p) como aquela que é «baseada no uso compartilhado de recursos, na construção coletiva de conhecimento, na interação livre de restrições de espaço e tempo e, na valorização do direito à informação, às tecnologias de informação e comunicação e à educação, como um bem comum». Essa sociedade exige que os cidadãos sejam preparados para a vida, que sejam críticos e tenham a capacidade de transformar a sua própria realidade, de inovar visando uma sociedade mais justa e solidária.

Tal realidade só será possível se a educação ofertada for de qualidade e para tanto, é necessário que se tenha, entre outros aspectos, o investimento e o devido cuidado com a formação e o trabalho do professor, pois, acredita-se que um professor melhor preparado poderá contribuir com a formação integral 
do sujeito e, consequentemente, com a sua integração como cidadão na sociedade em que vive. Entretanto, o cuidado com o trabalho docente ainda não é uma constante e entre os principais desafios observados ao longo do tempo observou-se a presença do mal-estar no trabalho do professor.

Considerando esses aspectos, o presente artigo buscará responder quais são os fatores que geram o mal-estar docente e de que forma influenciam na qualidade do trabalho docente?

\section{Contextualização do objeto investigado}

Durante as décadas de 1980 e 1990, pesquisas na área educacional demostravam que as problemáticas e os obstáculos da Educação tinham como foco principal os discentes, já que o processo educativo era centrado nos mesmos. Contudo, era necessário levar em consideração o profissional docente e aprofundar-se nas questões referentes a ele. Assim, as pesquisas sobre o exercício da docência, especialmente na Europa, começaram a apontar para discussões sobre as diversas dificuldades encontradas pelos professores, uma vez que a profissão já não era mais tão atraente. Desse modo, a figura do professor e suas práticas pedagógicas começaram a receber maior atenção dos pesquisadores (Rinaldi, 2016; Cunha, 2013; Diniz-Pereira, 2013; André, 2010). Debates sobre a insatisfação dos professores e suas condições de trabalho, carga horária e salário eram cada vez mais comuns. Contudo, foi somente a partir da década de 1990 que os debates ganharam relevância e fatores que teriam contribuído para a propagação do desencanto com a profissão ficaram mais evidentes.

A expressão mal-estar docente é utilizada para «descrever os efeitos permanentes, de caráter negativo, que afetam a personalidade do professor como resultado das condições psicológicas e sociais que exerce à docência, devido à mudança social acelerada» (Esteve, 1999:98). 0 autor ressalta que o mal-estar provoca as mais diversas reações nos docentes, tais como: sentimentos de insatisfação e de desajustamento perante os problemas reais da prática docente em contradição com a imagem ideal do professor; pedidos de transferência de escolas como uma maneira alternativa de fugir dos problemas; o desejo de desistir da docência; afastamento do trabalho; absentismo laboral, como 
forma de cortar a tensão acumulada; estresse, ansiedade, depreciação do eu (culpar a si mesmo perante a incapacidade de ter sucesso no ensino), reações neuróticas e depressões (Esteve, 1999).

Segundo Diniz-Pereira (2007) existe uma tendência bastante forte e recorrente no Brasil e em vários outros países, de se responsabilizar, e/ou de culpabilizar os professores e as professoras por todas as mazelas da educação escolar, ou pelo menos a maioria delas. De acordo com essa ideologia, melhorar a educação escolar implica em investir, única e exclusivamente, na formação dos docentes. Procura-se difundir a ideia de que a educação escolar está ruim porque os professores estão mal preparados para o exercício da profissão. Pouco se fala a respeito da necessidade da melhoria das condições de trabalho dos professores, desde o salário, a jornada de trabalho, a autonomia profissional, o número de alunos por sala de aula, até a situação de infraestrutura dos prédios escolares onde trabalham.

Essa ideologia é semelhante à outra, também bastante presente em nossa sociedade, que tende a responsabilizar e/ou culpabilizar a educação, ou melhor, a falta dela, - educação entendida aqui apenas como educação escolar -, por todas as desigualdades em nosso país. De acordo com essa ideologia, para os índices econômicos e de distribuição de renda melhorarem é preciso investir em educação - como se sabe, esse discurso da necessidade urgente de se investir em educação é bastante recorrente no Brasil, mas, infelizmente, dificilmente revertido em ações concretas.

Sabe-se também que essa ideologia desvia a atenção das pessoas da necessidade de se mudar o modelo e a política econômica do país para, então, melhorar os índices de distribuição de renda e para a implementação da justiça social, racial e econômica, ao mesmo tempo em que se invista maciçamente em educação. Não será a educação, e muito menos a formação docente, as únicas capazes de transformar a sociedade. A transformação da sociedade - «não aquela para manter as mesmas estruturas que alimentam as desigualdades sociais e econômicas - em direção a uma sociedade mais justa, mais humana e mais igualitária, não pode, porém, abdicar do importante papel da educação e da formação docente» (Diniz-Pereira, 2007:83-84).

Nesse cenário, julgamos necessário o olhar cuidadoso para o professor, pois se configura como ator que ocupa papel central na formação e integração do sujeito 
na sociedade. Nesse sentido, é necessário levar em consideração aspectos referentes ao trabalho desse profissional, como a sua saúde metal, emocional e física, uma vez que esses fatores podem refletir no trabalho desenvolvido cotidianamente e na qualidade do ensino.

\section{Metodologia}

O estudo organiza-se a partir da abordagem qualitativa da pesquisa em Ciências Humanas. Trata-se de uma revisão bibliográfica sistematizada, que abordou a temática do trabalho docente, com foco no mal-estar vivenciado pelos professores da educação básica, realizado em três etapas: definição da base de dados representativa e com credibilidade na área da Educação para o levantamento bibliográfico, definição dos unitermos e seleção dos materiais por relevância do tema, por fim, análise de conteúdo.

Para a padronização e organização do levantamento foram utilizados os seguintes unitermos: mal-estar docente; educação básica. A partir da análise dos títulos e unitermos das teses e dissertações da base da BDTD foram selecionados apenas os estudos que trataram do tema mal-estar docente na educação básica. Quando utilizamos os descritores «mal-estar docente; educação básica» apenas 11 trabalhos foram encontrados, ou seja, um número bem reduzido de pesquisas concluídas sobre a temática no período. Assim, refizemos a busca e utilizamos apenas o descritor «mal-estar docente» e encontramos um total de 102 trabalhos. Como o intuito era selecionar apenas os trabalhos com professores da educação básica, foi necessário realizar uma leitura dos resumos para seleção daqueles que comporiam o corpus a ser analisado, devido à falta de clareza do tema nos títulos e nas palavras-chave em alguns estudos. Foram selecionados ao final 51 trabalhos no período, sendo 8 teses e 43 dissertações.

Após a seleção, iniciou-se uma nova etapa de análise do material, em que foi realizada novamente a leitura dos resumos, entretanto, dessa vez expandimos a leitura para a seção de introdução e conclusão dos textos. A análise se deu com base no que propõe Bardin (2009) e Minayo (2010), a fim de compreender o que as teses e dissertações apontam sobre o trabalho e mal-estar docente da educação básica. 


\section{Resultados e discussões}

Os resultados do estudo corroboram nossa convicção de que o professor tem um papel fundamental e insubstituível no desenvolvimento da sociedade. Entretanto, alerta-nos sobre a necessidade premente de indução e investimento no desenvolvimento de sua profissionalidade para que possamos alcançar os resultados almejados no que tange ao

compromisso sustentado pelos países latino-americanos para o fortalecimento dos currículos, no que se refere à inclusão, dentro de seus conteúdos de aprendizagem, das aptidões, valores e atitudes para a vida, contribuirá para a incorporação de instrumentos necessários para superar a pobreza e melhorar a qualidade de vida das comunidades. Aulas e escolas que reconheçam as heterogeneidades dos estudantes, flexíveis nas respostas pertinentes às necessidades educacionais especiais, (...) profissionalização do docente como ator indiscutível de processos educacionais de qualidade, mediante capacitação, melhorias das condições de trabalho e remuneração. (UNESCO, 2004:53)

Nessa perspectiva, a análise do material sistematizado, nos permitiu perceber que diversos são os fatores que geram o mal-estar docente e, entre eles, aqueles que aparecem com maior ou menor frequência no desenvolvimento da atividade profissional.

De modo geral, no que se refere aos fatores que comparecem nas investigações com maior frequência, observa-se: o desprestígio ou desvalorização social da profissão docente (31\%), os baixos salários (27\%), a escassez de recursos (materiais e didáticos) (23\%) e o descaso da família dos alunos (19\%).

Entre aqueles fatores que apareceram com frequência moderada nas pesquisas analisadas, encontra-se: a longa jornada (14\%), a indisciplina (12 \%), a inclusão do aluno com deficiência (11\%), a sobrecarga de trabalho (11\%), a agressividade e violência (11\%), a ausência do trabalho coletivo (11\%), a falta de formação continuada ( $8 \%$ ), a infraestrutura da escola ( $8 \%$ ), a relação entre professores e alunos ( $8 \%$ ) e o excesso de alunos na sala de aula (8\%). Ainda, foi possível verificar os fatores que compareceram em números mais reduzidos nas pesquisas, como as relações interpessoais no trabalho, a falta de suporte ao professor, as avaliações sistemáticas dos alunos e as transformações da sociedade, onde cada fator, individualmente, representa $4 \%$. Fatores como 
os problemas de aprendizagem, a autoculpabilização e a imposição da lei que vai de encontro à falta de autonomia e o acúmulo de funções correspondem, cada um, a $3 \%$.

Há ainda fatores que compareceram minimamente, como a falta de apoio psicológico, o assédio moral e o bullying, a culpabilização do professor, a falta de tempo para o lazer, as demandas pela qualificação, as burocracias escolares e o descaso da direção da escola, sendo que cada fator representa $2 \%$. Finalmente, entre os fatores que menos comparecem nas investigações, com uma porcentagem de $1 \%$ cada, encontra-se: as renormalizações da atividade, as frequentes substituições, o plano de carreia deficitário, a alfabetização por tempo fixado, a contratação temporária, a rapidez das inovações tecnológicas, a instrumentalização da prática, a presença do outro (bolsista), a descontinuidade das atividades, o currículo pré- estabelecido, o choque com a realidade, a insegurança de vínculo no trabalho, a progressão continuada e as metas de produtividade.

A partir dos resultados apresentados é possível observar, que quatro fatores comparecem com mais intensidade entre aqueles que podem gerar ou agravar o mal-estar nos professores. A questão do desprestígio social e dos baixos salários na maioria das vezes foi concomitante, entretanto o desprestígio social acabou sobressaindo. 0 sentimento de desvalorização se dá justamente devido à baixa remuneração, a extenuante carga horária de trabalho, a ausência de recursos materiais, entre outros. Ainda, no que se refere à desvalorização, Lima (1996) aponta que a educação se tornou um tema em que todos os grupos sociais se veem no direito de opinar, resultando como destaca Bourdieu (1978, apud Lima, 1996), no desprestígio dos títulos dos profissionais da educação. Essa vulgarização dos assuntos educacionais influencia diretamente no trabalho do professor, uma vez que o mesmo se sente sem autoridade para tomar decisões que julgam corretas, além de ter que justificar suas ações devido as pressões advindas da instituição, do sistema de ensino por meio de mecanismos de avaliação e verificação de desempenho, da família.

Outro resultado chama nossa atenção entre os fatores que comparecem com maior frequência, que é o descaso por parte da família dos alunos. Esse fator ficou à frente de outros, como a longa jornada de trabalho e a indisciplina, que costumam receber muitas queixas por parte dos professores. Pereira (2011) 
ressalta a que ausência de participação da família do aluno, contribui com o mal-estar docente na medida em que a família atribui a tarefa de educar seus filhos como exclusividade do professor. Esse fato alinha-se a modificação do papel do professor (Esteve, 1999) que resulta em um acúmulo de funções docentes e, também, em um aumento de exigências em relação aos mesmos. Decorre daí a importância de se chamar a atenção, cf. apontado na introdução, para o fato de que o Estado e as famílias têm a sua parcela de responsabilidade no processo de formação e educação das crianças e adolescentes (cf. Brasil, 1988; 1996).

Outro fator que nos chama a atenção e aparece com frequência moderada nas produções analisadas é a ausência do trabalho coletivo. A esse respeito, Marcelo (2001) destaca que a organização da escola favorece o isolamento do professor.

El aislamiento de los profesores está favorecido evidentemente por la arquitectura escolar, que organiza las escuelas en módulos estándar, así como por la distribución del tiempo y el espacio, y la existencia de normas de independencia y privacidad entre los profesores (Marcelo, 2001:551).

O isolamento, a extenuante sobrecarga de atividades, as frágeis condições de trabalho e remuneração, muitas vezes, impossibilita o trabalho coletivo nas escolas, que contribui para a formação continuada do professor. Jesus (2002:42) reitera que «(...) a cooperação entre os professores pode ser o caminho para o bem-estar docente e para a inovação e a qualidade de ensino». Nesse sentido, o trabalho em equipe auxilia na diminuição do isolamento, no apoio e suporte mútuo e na troca de experiências.

Em relação às fontes de mal-estar que comparecem com baixa frequência notamos que muitos fatores compareceram nas pesquisas apenas uma vez, como é o caso da contratação temporária, do currículo pré-estabelecido e da rapidez das inovações tecnológicas. Nauroski (2014) analisou a condição dos professores temporários (PSS) no estado do Paraná em sua tese e constatou que:

Os professores, de modo geral, estão adoecendo e os PSS, quando adoecem, sofrem duplamente, primeiro pelas diferentes moléstias que os afligem e, segundo, de seu vínculo e os 
limites do seu contrato ao restringir seus direitos, como foi mostrado evidenciado, quando fizemos essa análise. (Nauroski, 2014:248)

Ainda de acordo com o autor, os professores no regime de trabalho PSS temem o futuro incerto do trabalho, tal elemento contribui com a sujeição e a resignação dos mesmos, potencializando o mal-estar nessa categoria docente (Nauroski, 2014).

O fator da contratação temporária pode ser considerado inovador nas pesquisas sobre o tema, considerando que o mesmo não costuma ser frequentemente abordado. Em nosso levantamento, conseguimos encontrar outras temáticas que seguem a mesma linha, entre elas a inclusão escolar de estudantes público-alvo da Educação Especial. Por exemplo, Bomfim (2008) revela que a inclusão de alunos com deficiência do ensino regular pode vir a provocar o mal-estar nos professores. Apesar de a autora destacar que a proposta de inclusão apenas acelerou o processo de eclosão de uma série de inquietações que vinham sendo sustentadas pelos professores há muito tempo, como por exemplo, a desvalorização profissional, os baixos salários, a falta de tempo para a capacitação, a excessiva carga horária, a ausência de material didático e a não participação da família do aluno. A autora destaca que:

O mal-estar vivenciado pelo professor é similar ao sentido pelos alunos com deficiência ou todos os demais que não possuem um lugar social. Nem a criança está na escola, nem o professor consegue reaver o respeito e o reconhecimento profissionais que tinha na sociedade. (Bomfim, 2008:223)

Outro trabalho explora a questão da progressão continuada e como essa prática influencia o mal-estar docente (Mairesse, 2003). Constatou-se que o professor sofria quando o aluno não aprendia, que os conflitos entre os professores e alunos aconteciam frequentemente e que o adoecer dos docentes resultava em licenças médicas.

A questão da ausência do trabalho coletivo também foi abordada em um estudo como uma das causas do mal-estar docente (Damasceno, 2002). A pesquisa mostrou que a troca de experiências que costuma ser enfatizada como uma das estratégias mais comuns para a construção de saberes dos professores e que auxilia no gerenciamento dos desafios da prática pedagógica entre pares 
encontra-se inibida na escola e que a cultura do individualismo é muito mais exercida do que a prática de trabalho coletivo.

Ainda, no estudo de Mendes (2015), no que se refere à avaliação externa, no caso o Índice de Desenvolvimento da Educação Básica (IDEB) verificou-se que a avaliação colabora para o sentimento de fracasso profissional, resultando em um adoecimento dos docentes. A autora ressalta que as avaliações externas contribuem para o fracasso educacional, uma vez que o desempenho escolar não é visto em sua "natura real», além do fato de os professores, alunos ou escola serem premiados ou punidos dependendo da nota atingida. Ainda sobre a temática, Cunha (2015) observou que os debates sobre avaliações externas ocupam uma grande parte do tempo da Aula de Trabalho Pedagógico Coletivo (ATPC) da escola, fazendo com que esse momento privilegiado que tem como objetivo providenciar uma formação continuada do docente acabe priorizando a discussão dos resultados das avalições externas e maneiras de aprimorá-los. Como consequência, o Projeto Político-Pedagógico (PPP) é posto em segundo plano, as metas e índices a serem atingidos são priorizados.

$\mathrm{Na}$ realidade, essas avaliações estimulam a competitividade entre os docentes, uma vez que eles recebem o bônus de mérito, caso venham a atingir o resultado desejável. Desse modo, o trabalho coletivo é minimizado pelas avaliações externas que pouco dizem sobre o trabalho realizado na escola e funcionam mais com um mecanismo de controle. Cunha (2015:414) ressalta que «as propostas inovadoras de trabalho expressas no PPP passam a ser atitudes marginais, uma subversão da ordem padronizadora das avaliações externas que levam ao treinamento dos alunos para os testes».

\section{Conclusões}

A legislação brasileira revela um movimento contraditório, dado que consideram a educação como direito fundamental, entretanto não dão as condições de trabalho necessárias aos professores, que diariamente enfrentam diversos desafios. Ou seja, o direito é anunciado, mas minimamente garantido, diante 
da precarização do trabalho docente e das escolas, além do pouco investimento financeiro à educação.

Ao retomarmos a questão orientadora do estudo foi possível perceber, que no período analisado, há a existência de várias reflexões e discussões sobre a temática do trabalho e mal estar docente. Os estudos analisaram o problema a partir de diferentes indicadores. No que se refere às causas, percebemos que os fatores que geram o mal-estar aparecem em frequência alta, média e baixa. Podemos destacar a questão do desprestígio social e dos baixos salários em meio aos fatores de alta frequência. Entre os indicadores de frequência média encontram-se a longa jornada, a indisciplina e a inclusão do aluno com deficiência. Os fatores de frequência baixa apresentaram uma grande diversidade, 29 indicadores de mal-estar foram encontrados, são exemplos: as relações interpessoais no trabalho, a falta de suporte ao professor e as avaliações sistemáticas dos alunos.

Percebeu-se também que o mal-estar, em geral, não é analisado articulado às políticas educacionais, apesar de as mesmas influenciarem diretamente o trabalho docente e funcionarem como catalizadores da intensificação e precarização do trabalho dos professores. Acreditamos que os achados iniciais que levam ao mal-estar estão diretamente ligados à implantação ou não das políticas educacionais.

Apesar das inúmeras pesquisas existentes sobre o mal-estar docente, o mesmo ainda continua sendo uma realidade entre os profissionais em exercício na educação básica. Nesse sentido, acreditamos ser pertinente a realização de mais estudos sobre o tema, articulando-o com as políticas públicas e educacionais. Para finalizar, destacamos que o professor é o principal agente que promove a atividade educacional e que a garantia de condições dignas de trabalho para o mesmo, entre outros aspectos, constitui elemento fundamental para atingir os objetivos visados pela educação. Tratar os professores com dignidade e respeito é cuidar não apenas da concretização de seus direitos, mas também facilitar que o direito à educação seja de fato cumprido. Se o direito à educação é considerado fundamental, a realidade vivenciada pelos docentes revela a necessidade da luta constante pela efetividade desse direito. 


\section{Referências bibliográficas}

André, M. (2010). Formação de professores: a constituição de um campo de estudos. Educação, 33(3, set./dez.), 174-181. Porto Alegre. Recuperado de http://revistaseletronicas.pucrs.br/ojs/index.php/faced/ article/view/8075/5719

Bardin, L. (2009). Análise de conteúdo. Lisboa: Edições 70.

Bomfim, A.P. (2008). A escuta na escola inclusiva: saberes e sabores do mal-estar docente. Dissertação (Mestrado) - Universidade de Brasília. Brasília.

Cunha, M. I. (2013). O tema da formação de professores: trajetórias e tendências do campo na pesquisa e na ação. Educação e Pesquisa, 39,(3, jul./set.), 609625. São Paulo. Recuperado de http://www.scielo.br/ pdf/ep/v39n3/aop1096.pdf

Cunha, R.C.O.B.; Barbosa, A.; Fernandes, M.J.S. (2015). Implicações das avaliações externas para o trabalho docente coletivo. Estudos em Avaliação Educacional, 26, 386-416. São Paulo. Recuperado de http://publicacoes.fcc.org.br/ojs/index.php/eae/article/ view/3288/3067

Damasceno, A.R. (2002). Da formação no corredor ao corredor de formação: a troca de experiência como alternativa para a gestão dos dilemas e desafios da prática pedagógica. Dissertação (Mestrado) - Universidade Federal de Minas Gerais. Belo Horizonte.

Dziekaniak, G.; Rover, A. (2011). Sociedade do Conhecimento: características, demandas e requisitos. Pesquisa Brasileira em Ciência da Informação e Biblioteconomia, 12(5).

Diniz-Pereira, J.E (2007). Formação de professores, trabalho docente e suas repercussões na escola e na sala de aula. Educação \& Linguagem, (15, jan./jun.), 82-98.
(2013). A construção do campo da pesquisa sobre formação de professores. Revista da FAEEBA - Educação e Contemporaneidade, 22(40, jul./dez.), 145-154. Salvador.

Dourado, L.F.; Oliveira, J.F. de (2009). A qualidade da educação: perspectivas e desafíos. Caderno Cedes, Campinas, 29(78, maio/ago.), 201-215.

Esteve, J.M. (1999). O mal-estar docente: sala de aula e a saúde dos professores. Trad. Cavicchia, D. de C. Bauru: EDUSC.

Hargreaves, A. (2004). Para além da padronização: comunidades de aprendizagem profissional ou seitas de treinamento para o desempenho? Em 0 ensino na sociedade do conhecimento: educação na era da insegurança (pp. 171-200). Trad. Costa, R. C. Porto Alegre: Artmed.

Jesus, S.N. de (2002). Perspectivas para o bem-estar docente. Uma lição de síntese. Porto: ASA.

Lima, J.A de (1996). O papel do professor nas sociedades contemporâneas. Educação, Sociedade \& Culturas, (6), 47-72.

Mairesse, C. (2003). Uma leitura psicanalítica da prática docente em turmas de progressão. Tese (Doutorado) - Universidade Federal do Rio Grande do Sul. Porto Alegre.

Marcelo, C. (2001). Aprender a enseñar para la Sociedad del Conocimiento. Revista Complutense de Educación, 12(2), 531-593.

Minayo, M. (2001). Ciência, técnica e arte: o desafio da pesquisa social. Em Minayo, M. C.S. (Org.). Pesquisa social: teoria, método e criatividade. Petrópoles: Vozes.

Mendes, M. (2015). A tradução do fracasso: burnout em professores do Recife. Tese (Doutorado) - Universidade Federal de Pernambuco, Recife. 
Nauroski, E.A. (2014). Trabalho docente e subjetividade: a condição dos professores temporários (PSS) no Paraná. Tese (Doutorado em Sociologia) - Universidade Federal do Paraná, Curitiba.

Oliveira, R.P. de; Araujo, G.C. de (2005). Qualidade do ensino: uma nova dimensão da luta pelo direito à educação. Revista Brasileira de Educação, (28, jan./abr.).

Pereira, F. (2011). Indicadores de mal-estar docente em escolas públicas municipais de Salvador. Dissertação (Mestrado em Educação) - Universidade Federal da Bahia, Salvador.

Rinaldi, R.P. (2016). Formação de professores: algumas considerações sobre o campo de pesquisa Em Militão, A.N.; Santana, M.S.R. (Orgs.). Intersecções entre pesquisas/pesquisadores experientes e pesquisas/ pesquisadores iniciantes no campo educacional (pp. 79-98). São Carlos: Pedro \& João Editores.

UNESCO (2004). Educação para todos na América Latina: um objetivo ao nosso alcance. Relatório Regional de Monitoramento de EPT 2003. Santiago: Trineo.

Fecha de recepción: 25/05/18 Fecha de aceptación: 10/09/18 